OPEN ACCESS

Edited by: Bernard Veldkamp

University of Twente, Netherlands

Reviewed by:

Caterina Fiorilli,

Libera Università Maria SS. Assunta,

Italy

Jesús Nicasio García Sánchez,

Universidad de León, Spain

*Correspondence:

Hao Lei

hlei@kcx.ecnu.edu.cn

Specialty section:

This article was submitted to Educational Psychology, a section of the journal

Frontiers in Psychology

Received: 14 November 2017 Accepted: 16 April 2018

Published: 07 May 2018

Citation:

Minghui L, Lei $H$, Xiaomeng $C$ and Potměšilc M (2018) Teacher Efficacy, Work Engagement, and Social Support Among Chinese Special Education School Teachers.

Front. Psychol. 9:648 doi: 10.3389/fpsyg.2018.00648

\section{Teacher Efficacy, Work Engagement, and Social Support Among Chinese Special Education School Teachers}

\author{
Lu Minghui ${ }^{1}, \mathrm{Hao}$ Lei $^{2 *}$, Chen Xiaomeng ${ }^{3}$ and Miloň Potměšilc ${ }^{4}$ \\ ${ }^{1}$ Special Education Department, School of Education, Guangzhou University, Guangzhou, China, ${ }^{2}$ Institute of Curriculum \\ and Instruction, East China Normal University, Shanghai, China, ${ }^{3}$ School of Education, South China Normal University, \\ Guangzhou, China, ${ }^{4}$ Institute of Special Education Studies, Faculty of Education, Palacký University, Olomouc, Czechia
}

This paper investigates the relationship between teacher efficacy and sociodemographic factors, work engagement, and social support among Chinese special education school teachers. The sample comprised 1,027 special education school teachers in mainland China. The Teachers' Sense of Efficacy Scale, the Multi-Dimensional Scale of Perceived Social Support, and the Utrecht Work Engagement Scale were used for data collection. Correlation analysis revealed that social support, work engagement, and teacher efficacy were significantly correlated with each other. Additionally, gender, years of experience, and monthly salary were significant predictors of teacher efficacy. Furthermore, structural equation modeling analysis showed that social support exerted its indirect effect on teacher efficacy through the mediation of work engagement. The findings of this study provide a new perspective on the complex association between social support and teacher efficacy. The explanations and limitations of these findings are discussed.

Keywords: Chinese special education school teachers, social support, teacher efficacy, work engagement

\section{INTRODUCTION}

In recent years, special education in China has changed in positive ways as a result of the government's education reforms. These changes include emphasizing the importance of teachers. The quality of teachers has been recognized as one of the most important factors in developing and improving special education in China (Wang and $\mathrm{Mu}, 2014$ ). Presently, the vast majority of students with special education needs are sent to special schools, and teachers in these schools face severe stress because of a paucity of practical training, high student-faculty ratios, insufficient facilities, and a shortage of professional skills (Lai et al., 2016; Zee et al., 2016). In order to teach effectively, teachers must compensate for this deficient teaching environment. The literature also shows that burnout occurs frequently among special education teachers (Sariçam and Sakiz, 2014). These phenomena indicate that teachers' characteristics merit further investigation so that specific interventions to improve their work may be developed. Traditionally, teachers' characteristics have been measured on the basis of subject knowledge, certification, and experience. However, in the past decade, research has also acknowledged the importance of teachers' attitudes and beliefs about their teaching to student progress and achievement (Ekstam et al., 2017). Therefore, it is also important to investigate factors, such as social context, job satisfaction, and work engagement, that contribute to shaping these beliefs. In China, it is particularly essential to assess such factors for special education school teachers comprehensively because of the high levels of cultural stigma 
that children with disabilities and their teachers face. However, there has been limited research on these issues in China.

\section{Teacher Efficacy}

The development of teacher efficacy is in part due to two similar learning theories: Rotter's social learning theory (1966) and Bandura's social cognitive theory (1977) (Tschannen-Moran and Hoy, 2001; McCarty, 2013). Teacher efficacy is defined as a teacher's beliefs or perceptions about his or her ability to teach students with different kinds of needs and to bring about desired changes in students' achievement (TschannenMoran et al., 1998). Studies have indicated that teacher efficacy is one of the most pervasive factors that potentially distinguishes teachers who teach effectively from those who usually struggle in teaching (Tschannen-Moran and Hoy, 2001). When examining teacher efficacy, researchers discovered that one teacher may have differing perceptions of efficacy when teaching different students or in varying situations. Teaching in a special education setting differs greatly from teaching students in a general education setting (McCarty, 2013). Special education school teachers are directly responsible for providing appropriate educational interventions for students who have speech disorders, cognitive deficiencies, attention deficit/hyperactivity disorder, or other behavioral problems (Skuller, 2011). The effectiveness of teachers' teaching ability, their persistence in the face of frustration, their instructional behaviors, and the performance of their students are influenced significantly by teacher efficacy (Pacheco and García, 2012; Dixon et al., 2014; Scherer et al., 2016). Therefore, it is important to perform a specific examination of special education school teachers' sense of teacher efficacy.

\section{Social Support}

Social support is defined as the provision of physical, emotional, informational, and instrumental assistance that an individual perceives from his or her social networks (Cobb, 1976; Lu et al., 2015). Social support encompasses a multitude of social interactions with one's spouse, extended family, friends, and others (Siklos and Kerns, 2006). Previous studies have found that teachers of special education in China are more likely to experience a sense of social isolation and prejudice than those in developed counties because of a general lack of public awareness about the meaning and significance of educating children with special needs (Mcloughlin et al., 2005; Zheng and Zheng, 2015). From this perspective, social support is of great significance in the process of fostering Chinese special education school teachers.

Studies have suggested that social support is an essential factor in teachers' efficacy and psychological state (Wallace et al., 2001; Shen, 2009) and that their psychological well-being can be enhanced by investing in their social context (Kruger, 1997; Field and Buitendach, 2012). Studies have also indicated that social support, both informal (e.g., from friends and relatives) and formal (e.g., from organizations), appears necessary for teachers to improve the quality of their teaching (Skaalvik and Skaalvik, 2009; Fiorilli et al., 2015). In special education, perceived social support might contribute to their openness to new experiences, feelings of burnout, and beliefs about teaching activities (Combee, 2014).

\section{Work Engagement}

Work engagement is characterized by vigor, dedication, and absorption. It represents a positive and psychologically fulfilling state of mind (Bakker et al., 2008). The concept has become a core indicator that reflects the quality of teachers' occupational lives by accounting for significant variation in the prediction of their occupational and organizational outcomes, such as teaching performance, problem solving, organizational commitment, and job satisfaction (Hakanen et al., 2006; Field and Buitendach, 2012). Furthermore, research has shown that work engagement was significantly and positively correlated with teacher efficacy (Hoigaard et al., 2012).

Work engagement may mediate between social support and teacher efficacy. According to the job demands-resources model, resources such as social support will help teachers cope with the emotional demands of teaching and will affect teachers' engagement (Hultell and Gustavsson, 2011). Previous studies also showed that changes in engagement levels are strongly tied to changes in senses of efficacy (Bresó et al., 2011). Although some ideas about how work engagement mediates teacher efficacy have been proposed in the research literature, few scholars have explored this key topic with regard to special education teachers.

\section{The Current Study}

At present, Chinese special education teachers suffer from prejudice and have to juggle numerous difficult tasks in addition to students' unique needs in their daily practice. However, to date, little research has been conducted about the relations among teacher efficacy, social support, and work engagement for special education.

The present investigation aims to contribute to our understanding of teacher efficacy and the related factors of socio-demographic factors, social support and work engagement among teachers at Chinese special education schools. Given the preceding rationale and the available literature, this study hypothesizes that teacher efficacy is associated with sociodemographic factors, social support, and work engagement. Specifically, the relationship between social support and teacher efficacy is mediated by work engagement. We hope that our study can provide evidence-based information that may prompt policy makers and professionals to provide better support for teachers at special education schools and assist them in adapting to their role, which would improve the quality of their teaching.

\section{MATERIALS AND METHODS}

\section{Participants}

The participants in this study comprised a convenience sample of 1027 special education teachers from special education schools in China. The 1027 participants included 232 males (24.6\%) and 775 females $(75.4 \%)$. The mean age of the sample was 36.22 years ( $S D=7.56$ years). The teachers' average experience in terms of years was $11.65(S D=6.31)$. The demographic characteristics of the participants are further illustrated in Table $\mathbf{1 .}$ 
TABLE 1 | Socio-demographic characteristics of the sample.

\begin{tabular}{lccc}
\hline Demographic variables & Female & Male & Total \\
\hline Number & $775(75.4 \%)$ & $252(24.6 \%)$ & $1027(100 \%)$ \\
Age $(M \pm S D)$ & $35.43 \pm 7.66$ & $38.21 \pm 7.39$ & $36.22 \pm 7.56$ \\
Years' experience $(M \pm S D)$ & $11.09 \pm 7.80$ & $13.81 \pm 7.99$ & $11.65 \pm 6.31$ \\
Monthly salary & & & \\
$\leq 4000$ RMB $(\$ 634.92)$ & 287 & 88 & $375(36.6 \%)$ \\
4000-6000 RMB & 268 & 96 & $364(35.4 \%)$ \\
$(\$ 634.92-\$ 952.38)$ & & & \\
6000-8000 RMB & 128 & 54 & $182(17.7 \%)$ \\
(\$952.38-\$1269.84) & & & \\
$\geq 8000$ RMB (\$1269.84) & 92 & 14 & $106(10.3 \%)$ \\
Whether satisfied with & & & \\
salary & & & \\
Satisfied with salary & 508 & 121 & $629(61.3 \%)$ \\
Not satisfied with salary & 267 & 131 & $398(38.7 \%)$ \\
\hline
\end{tabular}

1 US dollar is equal to approximately 6.30 RMB.

\section{Procedure}

The cross-sectional survey was conducted in mainland China. Teachers were selected from special education schools. A detailed description of the study, as well as the intended use of the results, was provided to each teacher. Participants were invited to complete a package of questionnaires, including a socio-demographic information questionnaire, the Teachers' Sense of Efficacy Scale (TSES), the Multi-Dimensional Scale of Perceived Social Support (MSPSS), and the Utrecht Work Engagement Scale (UWES). The questionnaire data were kept confidential in order to protect the anonymity of teachers. All the participating teachers were volunteers and did not receive any monetary compensation. All participants provided their written informed consent to participate in this study and the study was reviewed and approved by Human Research Ethics Committee for Non-Clinical Faculties (ethics committee from the School of Education, Guangzhou University) before the study began.

\section{Measures \\ Brief Demographic Questionnaire and Familial Profiles}

Questions were asked about the age, gender, education level, and marital status, as well as years of experience and monthly salary.

\section{Teachers' Sense of Efficacy Scale (TSES)}

The TSES was originally developed by Tschannen-Moran and Hoy (2001). The TSES is a reliable and valid instrument that measures a teacher's general sense of efficacy. It contains 24 items on a nine-point Likert scale and three subscale measures, including instructional strategies, classroom management, and student engagement $(1=$ nothing, $9=\mathrm{a}$ great deal). The total scale ranges from 24 to 216 , with higher scores indicating higher teacher efficacy. "Student engagement" refers to a teacher's behavior to ensure that students are actively engaged in the learning process, and "classroom management" means a teacher's ability to direct the flow of a class toward a set of learning objectives. Finally, "instructional strategies" encompass a teacher's competence in employing proper pedagogy to ensure student learning. In the current study, the Cronbach's alpha coefficient of TSES was 0.86 .

\section{Multi-Dimensional Scale of Perceived Social Support (MSPSS)}

The MSPSS was developed by Zimet et al. (1988). It consists of 12 items rated on a seven-point Likert scale and three subscale measures, including family support, friend support and other support $(1=$ very strongly disagree, $7=$ very strongly agree). The total score ranges from 12 to 84 , with higher scores indicating more perceived social support. The Chinese version of the MSPSS has good reliability and validity (Zhao et al., 2014; Tu and Yang, 2016). In the current study, the Cronbach's alpha coefficient for the MSPSS was 0.83 .

\section{Utrecht Work Engagement Scale (UWES)}

The Utrecht Work Engagement Scale (UWES) was developed by Schaufeli et al. (2002). It contains 17 items on a seven-point Likert scale and three subscale measures, including vigor, dedication, and absorption ( $0=$ never, 6 = always). Vigor is characterized by high levels of energy, resilience, and persistence in the face of obstacles and difficulties. Dedication refers to a sense of enthusiasm and inspiration. Absorption means full concentration on one's teaching tasks. The total score ranges from 0 to 102 , with high scores indicating greater levels of work engagement. The Chinese version of UWES has good reliability and validity (Li et al., 2015). In the current study, the Cronbach's alpha coefficient for the UWES was 0.87 .

\section{Statistical Analysis}

All statistical analyses were performed using SPSS 21.0 and AMOS 21.0. The statistical descriptions comprised the mean, standard deviation, frequencies, and percentages. Pearson's correlation analysis was calculated for social support, work engagement, and teacher efficacy. Hierarchical multiple regression analysis was performed to determine the associations of teacher efficacy, social support, and work engagement when controlling for socio-demographic factors. In the regression procedure, the total score for teacher efficacy was taken as the dependent variable. Independent variables were entered in the following order: socio-demographic factors in step 1; social support and work engagement subscales in step 2. All statistical tests were evaluated at the $p<0.05$ significance level and constituted two-tailed tests. The SEM procedure was employed to test how work engagement mediates the relationship between social support and teacher efficacy. Consistently with the recommendation of Zhonglin et al. (2004), the goodness of fit of the structural model was evaluated using the following indices: RMSEA (best if below 0.06), SRMR (best if below 0.08), NFI, CFI, TLI, IFI, and RFI (best if above 0.95). The research variables are further illustrated in Table 2. 
TABLE 2 | Descriptive statistics and correlations between the measured variables.

\begin{tabular}{|c|c|c|c|c|c|c|c|c|c|c|c|}
\hline & $M$ & $S D$ & 1 & 2 & 3 & 4 & 5 & 6 & 7 & 8 & 9 \\
\hline (1) FAS & 22.11 & 4.27 & 1 & & & & & & & & \\
\hline (2) FRS & 21.20 & 4.10 & $0.555^{* *}$ & 1 & & & & & & & \\
\hline (3) OS & 20.66 & 4.13 & $0.516^{* *}$ & $0.636^{* *}$ & 1 & & & & & & \\
\hline (4) VI & 20.03 & 8.69 & $0.192^{* *}$ & $0.210^{* *}$ & $0.278^{* *}$ & 1 & & & & & \\
\hline (5) $\mathrm{DE}$ & 17.18 & 8.03 & $0.181^{* *}$ & $0.243^{* *}$ & $0.274^{* *}$ & $0.758^{* *}$ & 1 & & & & \\
\hline (6) $A B$ & 18.95 & 6.37 & $0.219^{* *}$ & $0.270^{* *}$ & $0.318^{* *}$ & $0.710^{* *}$ & $0.741^{* *}$ & 1 & & & \\
\hline (7) SE & 48.03 & 9.44 & $0.375^{* *}$ & $0.329^{* *}$ & $0.330 * *$ & $0.251^{* *}$ & $0.208^{* *}$ & $0.236 * *$ & 1 & & \\
\hline (8) IS & 50.43 & 8.69 & $0.389^{* *}$ & $0.335^{* *}$ & $0.294^{* *}$ & $0.224^{* *}$ & $0.187^{* *}$ & $0.233^{* *}$ & $0.731^{* *}$ & 1 & \\
\hline (9) $\mathrm{CM}$ & 53.21 & 9.19 & $0.364^{* *}$ & $0.295^{* *}$ & $0.237^{* *}$ & $0.219^{* *}$ & $0.190^{* *}$ & $0.179 * *$ & $0.723^{* *}$ & $0.698^{* *}$ & 1 \\
\hline
\end{tabular}

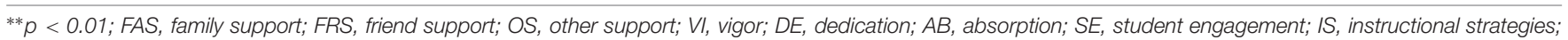
$\mathrm{CM}$, classroom management.

\section{RESULTS}

\section{Descriptive Analyses}

The means and standard deviations of the MSPSS, UWES, and TSES are shown in Table 2. Pearson correlations showed that the variables were significantly correlated. Pearson product-moment correlation coefficients were all positive and significant at the $p<0.01$ level.

\section{Multiple-Regression Analysis of Teacher Efficacy}

Table 3 summarizes the results of hierarchical multipleregression analysis. In step 1 of the analysis, socio-demographic factors accounted for 5.9\% $\left(R^{2}=0.059, p<0.01\right)$ of the variation in teacher efficacy, while the gender of the teachers, their years of experience, and their monthly salaries were

TABLE 3 | Hierarchical multiple regression results predicting teacher efficacy.

\begin{tabular}{|c|c|c|c|c|}
\hline \multirow[t]{2}{*}{ Predictor } & \multicolumn{2}{|c|}{ Step 1} & \multicolumn{2}{|c|}{ Step 2} \\
\hline & $\beta$ & $t$ & $\beta$ & $t$ \\
\hline \multicolumn{5}{|l|}{ Gender of teachers } \\
\hline Female & 0.091 & $2.356^{*}$ & 0.067 & $2.273^{*}$ \\
\hline Years' of experience & 0.197 & $6.536^{* *}$ & 0.134 & $4.548^{* *}$ \\
\hline \multicolumn{5}{|l|}{ Monthly salary } \\
\hline 4000-6000 RMB & 0.117 & $2.673^{*}$ & 0.054 & 1.099 \\
\hline 6000-8000 RMB & 0.165 & $2.972^{*}$ & 0.104 & $2.677^{*}$ \\
\hline$\geq 8000 \mathrm{RMB}$ & 0.281 & $3.185^{* *}$ & 0.189 & $2.915^{*}$ \\
\hline Family support & & & 0.246 & $6.730^{* *}$ \\
\hline Friend support & & & 0.168 & $4.117^{* *}$ \\
\hline Other support & & & 0.007 & 0.171 \\
\hline Vigor & & & 0.301 & $3.833^{* *}$ \\
\hline Dedication & & & 0.066 & 1.018 \\
\hline Absorption & & & 0.088 & 1.195 \\
\hline$R^{2}$ & 0.059 & & 0.256 & \\
\hline$F$ & $22.263^{* *}$ & & $40.507^{* *}$ & \\
\hline$\Delta \mathrm{R}^{2}$ & 0.059 & & 0.197 & \\
\hline$\Delta \mathrm{F}$ & $22.263^{* *}$ & & $15.379 * *$ & \\
\hline
\end{tabular}

${ }^{*} p<0.05,{ }^{* *} p<0.01$. statistically significant. The introduction of social support and work engagement subscales in step 2 accounted for $19.7 \%\left(R^{2}\right.$ change $\left.=0.197, p<0.01\right)$ of the variation in teacher efficacy. Steps 1 and 2 combined accounted for $25.6 \%\left(R^{2}=0.256, p<0.01\right)$ of the variance in teacher efficacy, while the gender of the teachers, their years of experience, support from family, support from friends, and the characteristic of vigor were statistically significant.

\section{The Mediating Effect of Work Engagement on the Relationship Between Social Support and Teacher Efficacy}

The SEM procedure was employed to test the proposed structural relationships among social support, work engagement, and teacher efficacy. The measurement model consisted of three latent factors (social support, work engagement, teacher efficacy) and nine observed variables. The mediational model, including both indirect pathways and direct pathways, was tested using chi-square differences. As shown in Table 4, the results demonstrated that the fit indices of the partial mediation model $\left(\chi^{2}=96.862, \mathrm{df}=24, p<0.001, \mathrm{RMSEA}=0.054,90 \%\right.$ $\mathrm{CI}=0.043-0.066, \mathrm{SRMR}=0.033, \mathrm{NFI}=0.980$, TLI $=0.978$, $\mathrm{CFI}=0.985$, IFI $=0.985, \mathrm{RFI}=0.970$ ) were good and met the psychometric standard. These results suggested that work engagement may play a partial mediating role in the relationship between social support and teacher efficacy. The standardized path coefficients for the partial mediation model are displayed in Figure 1.

The Bootstrap test was used to examine the significance of the mediating effects of work engagement on the relationship between social support and teacher efficacy. We generated 1000 bootstrapping samples from the original data set by random sampling. The results showed that the indirect effect was significant at the 0.01 level (indirect effect $=0.046, p<0.01,95 \%$ $\mathrm{CI}=0.022,0.073$ ), which accounted for $9.3 \%$ of the total effects (0.497).

These findings indicate that work engagement does indeed play a partial mediating role in the relationship between social support and teacher efficacy. 
TABLE 4 | Fit indices of the partial mediation model.

\begin{tabular}{|c|c|c|c|c|c|c|c|c|c|}
\hline$x^{2}$ & df & $\chi^{2 / d f}$ & RMSEA & SRMR & NFI & TLI & CFI & IFI & RFI \\
\hline 96.862 & 24 & 4.036 & 0.054 & 0.033 & 0.980 & 0.978 & 0.985 & 0.985 & 0.970 \\
\hline
\end{tabular}

$N=1027$.

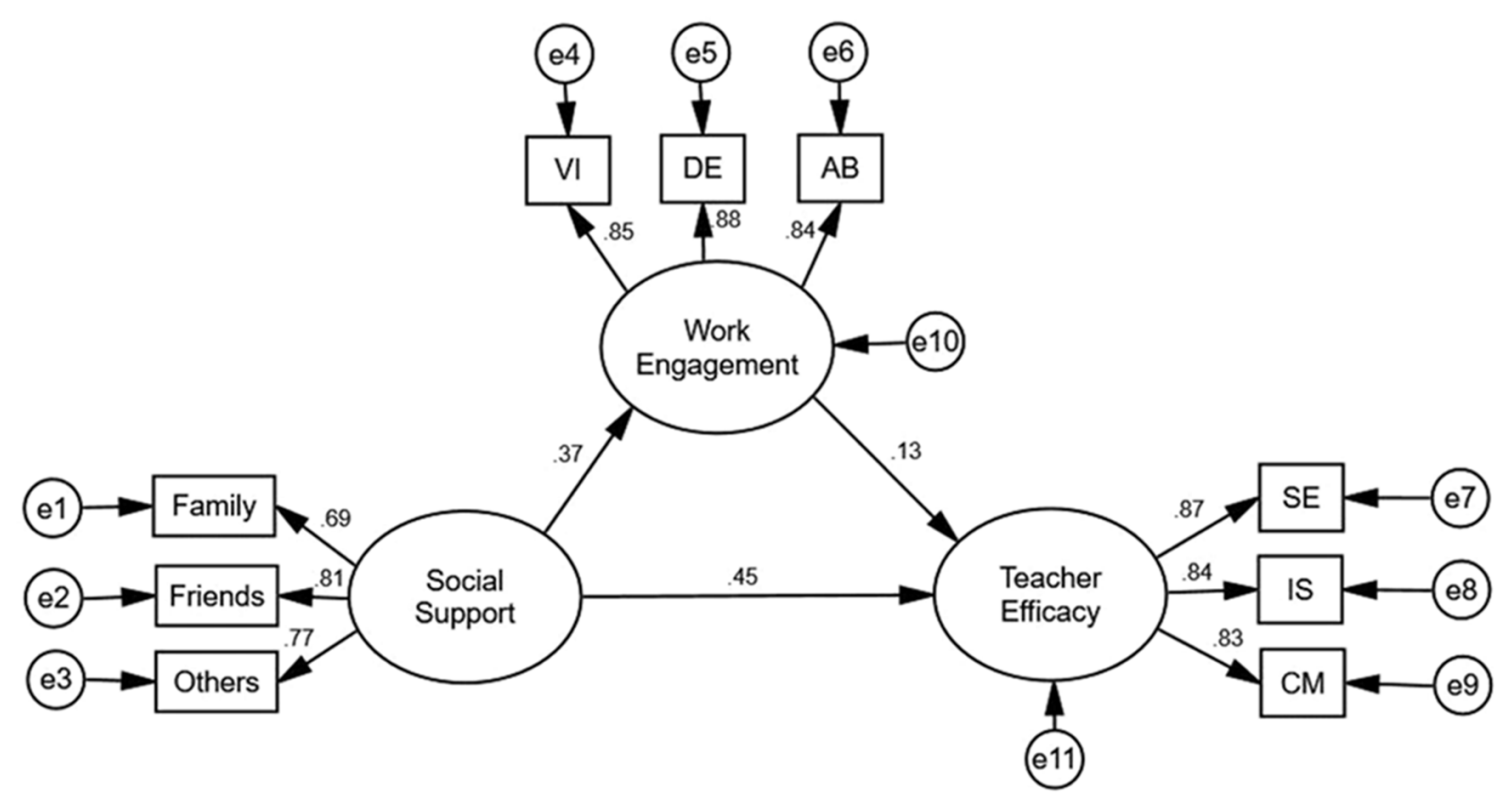

FIGURE 1 | The partial mediation model ( $N=1027)$. Factor loadings are standardized. The mediation model shows the independent variable (social support), mediator (work engagement), and dependent variable (teacher efficacy). Rectangles represent observed variables. Circles represent latent variables. VI, vigor; DE, dedication; AB, absorption; SE, student engagement; IS, instructional strategies; CM, classroom management.

\section{DISCUSSION}

In 2006, a national survey of China indicated that nearly 84 million people, or $6.34 \%$ of its population, have disabilities (Zhang and Spencer, 2015). However, education for people with disabilities has not received adequate attention until recent years, and the quality of teaching is still a universal challenge for most special education schools in China. Among the multiple indicators that reflect the quality of teaching, teacher efficacy has received widespread attention. However, little research has examined teacher efficacy in Chinese special education school teachers.

The current study investigated the prediction effect of socio-demographic factors, social support, and work engagement on teacher efficacy in Chinese special education schools. The following sections discuss the relationship of these selected variables.

\section{Associations Between Teacher Efficacy and Socio-Demographic Factors}

As shown in the present study, socio-demographic factors associated with teacher efficacy included gender, years of experience, and monthly salary. The present study found that female teachers outperformed male teachers in terms of teacher efficacy, which is consistent with a previous study conducted in Taiwan (Lee, 2000). According to the literature and practical situations, this result may reflect the existence of stereotype that a female teacher may be thought of as more suitable for work in special education when the Chinese cultural background is considered.

Monthly salary is a significant predictor of teacher efficacy. A previous study has suggested that there is a connection between teacher efficacy and salary (McCarty, 2013), and this study is consistent with the finding. In addition to mental and emotional burdens, special education school teachers bear the financial responsibility for supporting their families. As shown in the present study, approximately $61.3 \%$ of teachers are not satisfied with their monthly salaries. As a secondary intervention, financial support for teachers may contribute to a greater sense of well-being and thus better equip them to care for children with special needs.

Years of experience are another significant predictor of teacher efficacy; this finding is consistent with those of previous studies (Woolfolk and Hoy, 1990; Lamorey and Wilcox, 2005). As a result of the inadequate pre-service training in special education that Chinese teachers receive, on-the-job training and practice is the main way to improve teaching skills. This result suggests that, with more teaching experience, teachers may feel increasingly positive about their growing knowledge and skills, 
and therefore judge themselves as increasingly successful in special education.

\section{Associations Between Teacher Efficacy, Social Support, and Work Engagement}

The present study confirmed the associations between teacher efficacy, social support, and work engagement. Furthermore, hierarchical multiple regression analysis showed that only the characteristic of vigor and the support of family and friends, rather than other kinds of support or the characteristics of dedication or absorption, were significantly associated with teacher efficacy when controlling for socio-demographic factors. It is likely that different aspects of social support and work engagement weigh differently in their associations with teacher efficacy. Specifically, the support of family and friends and the characteristic of vigor play the most important roles.

\section{The Mediating Role of Work Engagement}

Although measures of social support and teacher efficacy are reliably correlated, the degree to which intervening variables mediate their relationship is not clear. This study provides evidence for the mediating role of work engagement in the relation between social support and teacher efficacy. Given the cross-sectional nature of the study, the results are open to multiple interpretations. One possible interpretation is that social support fosters work engagement; therefore, the internal psychological significance of social support actually promotes teacher efficacy. A second interpretation of the mediational model indicates that work engagement may prompt special education teachers to mobilize their social support resources. In particular, one's level of work engagement may encourage one to seek out support, as well as to utilize that support effectively. The way in which social support is used, in turn, may contribute to teacher efficacy. Thus, work engagement is transformed in some way by the properties of the teacher.

\section{Practical Implications}

Studies have shown that improvements in teacher efficacy can lead to enhanced job satisfaction and feelings of competence and can reduce the risk of burnout (Dixon et al., 2014; Sariçam and Sakiz, 2014). The hypothesis of the current study that work engagement serves as a mediator for the relationship between social support and teacher efficacy is supported by the results. In line with the expectations, the direct effect of social support on teacher efficacy was significant, that is, special education school teachers with high levels of social support were more likely to feel greater teacher efficacy. The mediating effect of work engagement on the relationships between social support and teacher efficacy was significant. In other words, social support indirectly affected teacher efficacy through work engagement. On a clinical level, to improve teacher efficacy, it is important to implement interventions that strengthen work engagement by fostering social support systems in the whole society. A previous study indicated that teachers' engagement can be fostered through the satisfaction of basic psychological needs (Klassen et al., 2012). Thus, it is important to reduce the social, emotional, physical, and even financial burdens of teachers working in special education schools in China, and to provide productive feedback about effective teaching in order to foster work engagement and personal achievement among teachers in special education schools. Another important way to promote teacher efficacy is through mastery experiences. Professional development activities, such as training, tutoring, and observations, can have a positive impact on teacher efficacy (Haverback and Parault, 2008).

Most importantly, each country, while learning from the successful experiences of other countries, has to examine and improve its own system within its own unique cultural, economic, political, and policy contexts (Ellsworth and Zhang, 2007). While the understanding of special education is increasing among service providers in China, the general population commonly holds inaccurate views of children with disabilities and their teachers. On the basis of such realities, it is essential to make varied efforts to enhance social support more effectively. Social support can emerge from multiple sources, and should be considered in a wider ecological context beyond family, friends, and significant others. It is apparent that professional support systems need to be developed for teachers in special education schools, and that more public education campaigns are needed to raise awareness of special education and reduce any associated stigma.

\section{CONCLUSION}

This study helps to improve understanding of social support, work engagement, and the socio-demographics factors that are associated with teacher efficacy among Chinese special education school teachers. In conclusion, teacher efficacy was associated with gender, years of experience, monthly salary, the support of family, the support of friends, and the characteristic of vigor. Work engagement mediates between social support and teacher efficacy.

\section{LIMITATIONS}

The strengths of the present study lie first in the methodology used for the sampling and the large sample size. In addition, validated instruments enhance the accuracy of the findings and make cross-cultural comparisons possible.

Despite the above strengths, this study should be considered in light of several limitations. First, considering the distinct socioeconomic and cultural characteristics of China, our findings may not simply be generalized to other countries. Second, the data were collected through self-report questionnaires that largely depend on subjective observation, which may raise questions about accuracy. Third, other factors, such as social environments and teaching practice, may also affect teacher efficacy, which should be considered in future studies. Finally, it is also important to note that the questionnaires 
were obtained through the pencil and paper method and future research could obtain data in a virtual way through a professional survey application such as SurveyMonkey, which would speed up the data collection and avoid errors.

\section{AUTHOR CONTRIBUTIONS}

LM and LH provided the idea, designed this study and wrote the manuscript. CX contributed to data analysis and data collection. MP contributed to revised this manuscript.

\section{REFERENCES}

Bakker, A. B., Schaufeli, W. B., Leiter, M. P., and Taris, T. W. (2008). Work engagement: an emerging concept in occupational health psychology. Work Stress 22, 187-200. doi: 10.1080/02678370802393649

Bresó, E., Schaufeli, W. B., and Salanova, M. (2011). Can a self-efficacy-based intervention decrease burnout, increase engagement, and enhance performance A quasi-experimental study. High. Educ. 61, 339-355. doi: 10.1007/s10734-0109334-6

Cobb, S. (1976). Social support as a moderator of life stress. Psychosom. Med. 38, 300-314. doi: 10.1097/00006842-197609000-00003

Combee, S. W. (2014). The Relationship Between Administrative Support and Teacher Efficacy in the Professional Life of Special Education Teacher. Doctoral dissertation, Virginia Commonwealth University, Richmond, VA.

Dixon, F. A., Yssel, N., McConnell, J. M., and Hardin, T. (2014). Differentiated instruction, professional development, and teacher efficacy. J. Educ. Gift. 37, 111-127. doi: 10.1177/0162353214529042

Ekstam, U., Korhonen, J., Linnanmäki, K., and Aunio, P. (2017). Special education pre-service teachers' interest, subject knowledge, and teacher efficacy beliefs in mathematics. Teach. Teach. Educ. 63, 338-345. doi: 10.1016/j.tate.2017. 01.009

Ellsworth, N. J., and Zhang, C. (2007). Progress and challenges in China's special education development. Remedial Spec. Educ. 28, 58-64. doi: 10.1177/ 07419325070280010601

Field, L. K., and Buitendach, J. H. (2012). Work engagement, organisational commitment, job resources and job demands of teachers working within disadvantaged high schools in KwaZulu-Natal, South Africa. J. Psychol. Afr. 22, 87-95. doi: 10.1080/14330237.2012.10874525

Fiorilli, C., Gabola, P., Pepe, A., Meylan, N., Curchod-Ruedi, D., Albanese, O., et al. (2015). The effect of teachers' emotional intensity and social support on burnout syndrome. A comparison between Italy and Switzerland. Rev. Eur. Psychol. Appl. 65, 275-283. doi: 10.1016/j.erap.2015. 10.003

Hakanen, J. J., Bakker, A. B., and Schaufeli, W. B. (2006). Burnout and work engagement among teachers. J. Sch. Psychol. 43, 495-513. doi: 10.1016/j.jsp. 2005.11.001

Haverback, H. R., and Parault, S. J. (2008). Pre-service reading teacher efficacy and tutoring: a review. Educ. Psychol. Rev. 20, 237-255. doi: 10.1007/s10648-0089077-4

Hoigaard, R., Giske, R., and Sundsli, K. (2012). Newly qualified teachers' work engagement and teacher efficacy influences on job satisfaction, burnout, and the intention to quit. Eur. J. Teach. Educ. 35, 347-357. doi: 10.1080/02619768. 2011.633993

Hultell, D., and Gustavsson, J. P. (2011). Factors affecting burnout and work engagement in teachers when entering employment. Work 40, 85-98. doi: 10. 3233/WOR-2011- 1209

Klassen, R. M., Aldhafri, S., Mansfield, C. F., Purwanto, E., Siu, A. F. Y., Wong, M. W., et al. (2012). Teachers' engagement at work: an international validation study. J. Exp. Educ. 80, 317-337. doi: 10.1080/00220973.2012.678409

Kruger, L. J. (1997). Social support and self-efficacy in problem solving among teacher assistance teams and school staff. J. Educ. Res. 90, 164-169. doi: 10.1080/ 00220671.1997 .10543772

\section{FUNDING}

This work was supported by grants from the Guangdong Philosophy and Social Science project (Grant No. GD17YJY02), Research Foundation of Guangzhou University (Grant No. 27000503166), and the research project Palacký University Olomouc (Czechia) (Grant No. IGA_PdF_2017_021).

\section{ACKNOWLEDGMENTS}

We thank all the teachers that participated in this study.

Lai, F. T. T., Li, E. P. Y., Ji, M., Wong, W. W. K., and Lo, S. K. (2016). What are the inclusive teaching tasks that require the highest self-efficacy? Teach. Teach. Educ. 59, 338-346. doi: 10.1016/j.tate.2016.07.006

Lamorey, S., and Wilcox, M. J. (2005). Early intervention practitioners' self-efficacy: a measure and its applications. Early Child. Res. Q. 20, 69-84. doi: 10.1016/j. ecresq.2005.01.003

Lee, T. (2000). Investigating Confidence and Efficacy of Special Education Preservice Teaching in Traditional and Alternative Teacher Education Programs in Taiwan. Doctoral dissertation, Oklahoma State University, Stillwater, OK.

Li, M., Wang, Z., You, X., and Gao, J. (2015). Value congruence and teachers' work engagement: the mediating role of autonomous and controlled motivation. Pers. Individ. Dif. 80, 113-118. doi: 10.1016/j.paid.2015. 02.021

Lu, M., Yang, G., Skora, E., Wang, G., Cai, Y., Sun, Q., et al. (2015). Self-esteem, social support, and life satisfaction in Chinese parents of children with autism spectrum disorder. Res. Autism Spectr. Disord. 17, 70-77. doi: 10.1016/j.rasd. 2015.05.003

McCarty, K. A. (2013). The Relationship Between Special Education Teacher's Sense of Teacher Efficacy and their Intent to Leave. Doctoral dissertation, Azusa Pacific University, Azusa, CA.

Mcloughlin, C. S., Zhou, Z., and Clark, E. (2005). Reflections on the development and status of contemporary special education services in China. Psychol. Sch. 42, 273-283. doi: 10.1002/pits.20078

Pacheco, D. I., and García, J. N. (2012). "The quality of teaching determines students' achievement in writing," in Learning Disabilities, ed. W. Sittiprapaporn (Rijeka: InTech), 175-194. doi: 10.5772/32531

Sariçam, H., and Sakiz, H. (2014). Burnout and teacher self-efficacy among teachers working in special education institutions in Turkey. Educ. Stud. 40, 423-437. doi: 10.1080/03055698.2014.930340

Schaufeli, W. B., Salanova, M., Roma, V. G., and Bakker, A. B. (2002). The measurement of engagement and burnout: a two sample confirmatory factor analytic approach. J. Happiness Stud. 3, 71-92. doi: 10.1023/A:101563093 0326

Scherer, R., Jansen, M., Nilsen, T., Areepattamannil, S., and Marsh, H. W. (2016). The quest for comparability: studying the invariance of the teachers' sense of self-efficacy (TSES) measure across countries. PLoS One 11:e150829. doi: 10.1371/journal.pone.0150829

Shen, Y. E. (2009). Relationships between self-efficacy, social support and stress coping strategies in Chinese primary and secondary school teachers. Stress Health 25, 129-138. doi: 10.1002/smi.1229

Siklos, S., and Kerns, K. A. (2006). Assessing need for social support in parents of children with autism and down syndrome. J. Autism Dev. Disord. 36, 921-933. doi: 10.1007/s10803-006-0129-7

Skaalvik, E. M., and Skaalvik, S. (2009). Does school context matter? Relations with teacher burnout and job satisfaction. Teach. Teach. Educ. 25, 518-524. doi: 10.1016/j.tate.2008.12.006

Skuller, J. B. (2011). Teacher Efficacy, Teacher Burnout, and Attitudes Towards Students with Autism. Doctoral dissertation, University of Louisville, Louisville, KY.

Tschannen-Moran, M., and Hoy, A. W. (2001). Teacher efficacy: capturing an elusive construct. Teach. Teach. Educ. 17, 783-805. doi: 10.1016/S0742051X(01)00036-1 
Tschannen-Moran, M., Hoy, A. W., and Hoy, W. K. (1998). Teacher efficacy: its meaning and measure. Rev. Educ. Res. 68, 202-248. doi: 10.3102/ 00346543068002202

Tu, Y., and Yang, Z. (2016). Self-control as mediator and moderator of the relationship between social support and subjective well-being among the Chinese elderly. Soc. Indic. Res. 126, 813-828. doi: 10.1007/s11205-0150911-z

Wallace, K. A., Bisconti, T. L., and Bergeman, C. S. (2001). The mediational effect of hardiness on social support and optimal outcomes in later life. Basic Appl. Soc. Psychol. 4, 267-279. doi: 10.1207/S15324834BASP2 304_3

Wang, Y., and Mu, G. M. (2014). Revisiting the trajectories of special teacher education in China through policy and practice. Int. J. Disabil. Dev. Educ. 61, 346-361. doi: 10.1080/1034912X.2014.955792

Woolfolk, A. E., and Hoy, W. K. (1990). Prospective teachers' sense of efficacy and beliefs about control. J. Educ. Psychol. 82, 81-91. doi: 10.1037/0022-0663. 82.1 .81

Zee, M., de Jong, P. F., and Koomen, H. M. Y. (2016). Teachers' self-efficacy in relation to individual students with a variety of social-emotional behaviors: a multilevel investigation. J. Educ. Psychol. 108, 1013-1027. doi: 10.1037/ edu0000106

Zhang, D., and Spencer, V. G. (2015). Addressing the needs of students with autism and other disabilities in China: perspectives from the field. Int. J. Disabil. Dev. Educ. 62, 168-181. doi: 10.1080/1034912X.2014. 998175
Zhao, J., Wang, Y., and Kong, F. (2014). Exploring the mediation effect of social support and self-esteem on the relationship between humor style and life satisfaction in Chinese college students. Pers. Individ. Dif. 64, 126-130. doi: 10.1016/j.paid.2014.02.026

Zheng, Y., and Zheng, X. (2015). Current state and recent developments of child psychiatry in China. Child Adolesc. Psychiatry Ment. Health 9, 1-10. doi: 10. 1186/s13034-015-0040-0

Zhonglin, W., Kit-Tai, H., and Marsh, H. W. (2004). Structural equation model testing: cutoff criteria for goodness of fit indices and chi-square test. Acta Psychol. Sin. 36, 186-194.

Zimet, G. D., Dahlem, N. W., Zimet, S. G., and Farley, G. K. (1988). The multidimensional scale of perceived social support. J. Pers. Assess. 52, 30-52. doi: 10.1207/s15327752jpa5201_2

Conflict of Interest Statement: The authors declare that the research was conducted in the absence of any commercial or financial relationships that could be construed as a potential conflict of interest.

Copyright (c) 2018 Minghui, Lei, Xiaomeng and Potměšilc. This is an open-access article distributed under the terms of the Creative Commons Attribution License (CC BY). The use, distribution or reproduction in other forums is permitted, provided the original author(s) and the copyright owner are credited and that the original publication in this journal is cited, in accordance with accepted academic practice. No use, distribution or reproduction is permitted which does not comply with these terms. 